\title{
Characterization of a novel Minute-locus in Drosophila melanogaster: a putative ribosomal protein gene
}

\author{
Stefan Andersson and \\ Andrew Lambertsson
}

Department of Genetics, University of Umeå, S-901 87 Umeå, Sweden.

\begin{abstract}
We describe a novel Minute locus, $M(1) 7 C$, on the X-chromosome of Drosophila melanogaster. Heterozygous deficient females have most, if not all, of the Minute features (short and fine bristles, rough and somewhat larger eyes, thintextured wings, missing aristae, affected antennae, delayed development, reduced fertility, and decreased viability). Both Minute and non-Minute adult progeny from Minute mothers suffer from Minute maternal effects such as abdominal segmentation defects, fused tergites, and missing or defective legs and halteres. Using a plasmid clone from region 7C5-9, which harbours the $D$. melanogaster ribosomal protein gene $R P S 14$, we have found that the accumulation of a single transcript of $\sim 650 \mathrm{~b}$ is extremely reduced in Minute larvae in comparison with wild-type. We have localized the RPS14 gene to $\sim 28 \mathrm{kbp}$ distal from the singed locus. The results suggest that $M(1) 7 C$ and $R P S 14$ may be the same gene.
\end{abstract}

\section{INTRODUCTION}

The Minute mutations of Drosophila melanogaster are a class of 40-50 loci that cause thin, short bristles, delay development time, reduce female fertility, decrease viability, produce rough eyes, small body size, thin wings, and etched tergites (Lindsley and Grell, 1968). In homozygous or hemizygous condition, Minute mutants are lethal and die at about the time of egg hatching. A heterozygous deficiency for a Minute locus produces a Minute phenotype.

It has been suggested that the Minute loci are the loci for tRNAs (Ritossa et al. 1966) or for ribosomal proteins (for review see Kay and JacobsLorena, 1987). In the course of cloning the dec-1 locus (cytological position 7C3-4; A. Lambertsson, T. Johansson, and S. Andersson, unpublished results) by a chromosome walk from the singed locus $(1-21 \cdot 0 ; 7 \mathrm{D} 1-2)$ we observed that several heterozygous deficiencies uncovering the region 7C5-9 produced Minute phenotypes. This interval of the X-chromosome has been reported to contain a haplo-lethal locus (Lefevre Jr. and Johnson, 1973), and a ribosomal protein gene, RPS 14 (Brown et al., 1988). It has been suggested that Minutes code for ribosomal proteins (Burns et al., 1984; Vaslet et al., 1980) but only one, $M(3) 99 D$, has been shown to do so (Kongsuwan et al., 1985).
We therefore decided to examine this region for the presence of a Minute locus. The results presented here show that a novel Minute locus, $M(1) 7 C$, is located in the 7C5-9 region, and that the accumulation of the RPS14 mRNA is extremely reduced in Minute larvae in comparison with wild-type.

\section{MATERIALS AND METHODS}

\section{Drosophila stocks and fly handling}

Flies were raised on standard potatomash, yeast and agar substrate at various temperatures $-17^{\circ}$, $25^{\circ}, 29^{\circ} \mathrm{C}$ as well as room temperature $\left(20-23^{\circ} \mathrm{C}\right)$.

The haplolethal $(h l)$-deficiencies listed below were a kind gift from $\mathrm{Dr}$ M. Gans. They were originally recovered in an X-ray screen performed by $\mathrm{Dr} F$. Forquignon. Details about the $D p(1 ; 2) s n^{+72 d}$ strain can be found in Lindsley and Zimm (1987). The wild-type stock used here was Shahrinau, obtained from the European Drosophila Stock Center, Umeå, Sweden.

$$
\begin{aligned}
& C(1) D X, y f / w c v D f(1) h l^{a} B ; \\
& D p(1 ; 2) s n^{+72 d} / b w^{D} \\
& C(1) D x, y f / D f(1) h l^{b} ; D p(1 ; 2) s n^{+72 d} / b w^{D} \\
& C(1) D X, y f / D f(1) h l^{c} ; D p(1 ; 2) s n^{+72 d} / b w^{D} \\
& C(1) D X, y f / c m D f(1) h l^{d} f ; \\
& D p(1 ; 2) s n^{+72 d} / b w^{D}
\end{aligned}
$$




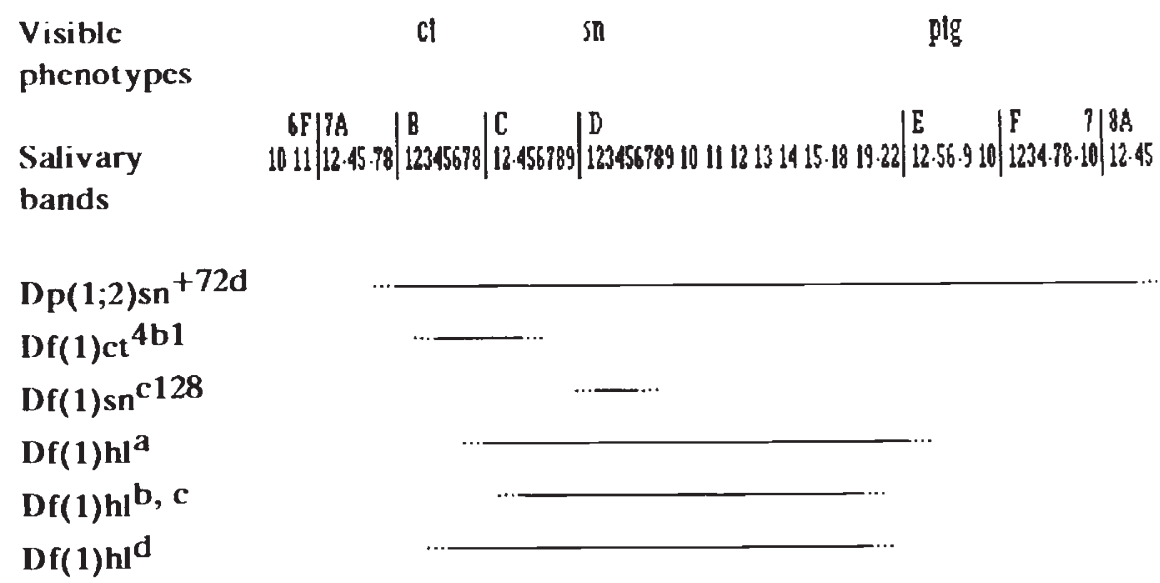

Figure 1 Schematic representation of cytological region $6 \mathrm{~F} 10-11$ to $8 \mathrm{~A} 1-5$ on the X-chromosome also indicating the positions of $c t=c u t, s n=$ singed and $p t g=$ pentagon, and the approximate extensions of the duplication and deficiencies used in this study.

The approximate lengths of these deficiencies and other chromosal rearrangement used in this study are given in fig. 1 .

\section{Crosses}

Shahrinau females, 2-5 days old (five in each tube), were mated with males carrying an $h l$-deficiency and the duplication covering the 7C5-9 region (see above). After 2 days eggs were collected for 2-4 h in tubes with fresh substrate. After discarding the parents the tubes were kept at the temperatures indicated. Of the G1 females those carrying the duplication hatched normally whereas the deficiency heterozygotes, phenotypically $b w^{D}$, hatched several days later. The latter females were collected and further examined for typical Minute characters.

\section{Northern Blot Analysis}

Total RNA from wild-type and Minute larvae, and wild-type ovaries was prepared and fractionated on 1 per cent agarose-formaldehyde gels as described previously (Hansson and Lambertsson, 1983). Due to their delayed development, $M(1) 7 C$ larvae are easily recognized in a synchronized larval population. All blotting onto GeneScreen Plus filters (Dupont, NEN Research Products) was carried out using the VacuGene Vacuum Blotting System (Pharmacia LKB Biotechnology AB).

The filter was hybridized at $60^{\circ} \mathrm{C}$ for $12-18 \mathrm{hr}$ in 1 per cent SDS (sodium dodecyl sulphate), $1 \mathrm{M}$ sodium chloride, 10 per cent dextran sulphate, and $200 \mu \mathrm{g} / \mathrm{ml}$ of sonicated and denatured salmon sperm DNA. Final concentration of the probe was $4 \times 10^{5} \mathrm{cpm} / \mathrm{ml}$.

After removal of the filter from hybridization solution it was washed in $2 \times 100 \mathrm{ml}$ of $2 \times \mathrm{SSC}$ $(0.3 \mathrm{M}$ sodium chloride and $0.03 \mathrm{M}$ sodium citrate) at room temperature for 5-10 min with constant agitation. Next, the filter was washed in $2 \times 200 \mathrm{ml}$ of 1 per cent SDS and $2 \times \mathrm{SSC}$ at $60^{\circ} \mathrm{C}$ for $30 \mathrm{~min}$ with constant agitation, and finally in $2 \times 100 \mathrm{ml}$ of $0 \cdot 1 \times \mathrm{SSC}$ at room temperature for 30 min with constant agitation.

\section{Probes}

The duplicated $D$. melanogaster ribosomal protein gene RPS14, cloned in Bluescript M13+ (pGS14$19)$, was used as probe. It was generously provided by Drs D. Rhoads and D. Roufa. pRH0.75 is a pBR322 plasmid clone containing most of the $S g s 4$ gene (salivary gland secretion; Hansson and Lambertsson 1983). The $\alpha$-tubulin probe, which is cloned in pGEM-2, was kindly supplied by $\mathrm{Dr} \mathrm{M}$. Bownes. The probes were labeled with ${ }^{32} \mathrm{P}$-dCTP by primer extension following the supplier's instructions (Amersham or Promega Biotech).

\section{RESULTS AND DISCUSSIONS}

Minute phenotypes produced by 7C5-9 heterozygous deficiencies

\section{Decreased viability}

As shown in fig. 1 the $h l$-deficiencies used in this study have different lengths. $D f(1) h l^{b, c}$ are 
Table 1 Viability of offspring from crosses between Shahrinau wild-type females and $D f(1) h l^{b}$ or $D f(1) h l^{c}$ males; for complete genotypes see Materials and Methods. The data from the crosses are pooled

\begin{tabular}{llllll}
\hline & & \multicolumn{3}{c}{ Adults eclosed } \\
\cline { 3 - 6 } Eggs & Larvae & $\begin{array}{l}+/ D f(1) h l^{b, c} ; \\
+/ D p(1 ; 2)\end{array}$ & $\begin{array}{l}+/ D f(1) h l^{b, c} ; \\
+/ b w^{D^{*}}\end{array}$ & $\begin{array}{l}+/ Y ; \\
+/ D p(1 ; 2)\end{array}$ & $\begin{array}{l}+/ Y ; \\
+/ b w^{D}\end{array}$ \\
\hline 747 & 692 & 173 & 59 & 134 & 173 \\
\hline
\end{tabular}

* These females are Minute.

approximately of the same size and smaller than $D f(1) h l^{a, d}$ (M. Gans, personal communication). However, the exact positions of the breakpoints of these deficiencies are not known at the present time.

Having observed that crosses between $h l$ deficient males carrying $D p(1 ; 2) s n^{+72 d}$ and wildtype females produced very late-hatching heterozygous deficient $b w^{D}$ females we decided to analyze further the nature of these females from each of the four $h l$-deficient males.

Males from each of the four $h l$-deficiencies carrying $D p(1 ; 2) s n^{+72 d}$ were mated to wild-type females as described in Materials and Methods. Crosses involving $D f(1) h l^{a, d}$ males produced very few $b w^{D}$ females, and this is very likely due to the larger extension of these deficiencies in comparison with $D f(1) h l^{b, c}$ (see below).

In crosses at $25^{\circ} \mathrm{C}$ between Shahrinau wild-type females and males carrying $D f(1) h l^{b}$ or $D f(1) h l^{c}$ 92 per cent of the eggs laid hatched as larvae, and 72 per cent eclosed as adults (table 1). As shown in table 1 the number of Minute $\left(b w^{\mathrm{D}}\right)$ females is only $1 / 3$ of that of the wild-type females carrying $D p(1 ; 2) s n^{+72 d}$ or 25 per cent of the females $(n=$ 232), and this explains the reduced number of flies hatched. In addition, the number of males carrying the duplication is slightly reduced in comparison to the $+; b w^{D}$ males (table 1 ). This is very likely due to reduced viability of the former males, which have been shown to be almost completely sterile (Gans et al., 1980). We also noted that females being $b w^{D}$, and thus heterozygous for the deficiency, hatched considerably later when compared to wild-type or deficiency-heterozygotes carrying $D p(1 ; 2) s n^{+72 d}$ (see below under Development).

To study further the viability of Minutes the crosses described above were repeated at $17^{\circ}, 25^{\circ}$, and $29^{\circ} \mathrm{C}$. The results from these crosses are summerized in fig. 2. At $25^{\circ} \mathrm{C}$ (fig. 2B) the number of Minute females is $1 / 3$ of the wild-type females carrying the duplication or 25 per cent of the flies hatched $(n=64)$, and this is in accordance with the results described above (table 1). Surprisingly, however, at $17^{\circ} \mathrm{C}$ (fig. 2(A)) the Minute flies constitute 41 per cent $(n=87)$ of the females, and at $29^{\circ} \mathrm{C}$ (fig. $\left.2(\mathrm{C})\right) 42$ per cent $(n=100)$. Speculating that the Minute locus in 7C5-9 codes for a ribosomal protein or some other component of the translational machinery, this result is very interesting in that Minute flies would be expected to have reduced protein synthesis rates at higher temperatures. Consequently, the viability would be higher at lower temperatures and not at $29^{\circ} \mathrm{C}$ as observed here. We are presently planning experiments to study further this rather unexpected result.

When examining the progeny of $D f(1) h l^{a, d}$ males, crossed to Shahrinau females, we found that they produce non-Minute adults in the expected ratio. However, no adult Minute progeny emerged simply because the pupae died at different stages during pupal development. Since these deficiencies extend both proximally and distally (7B3-4; 7E1-2) relative to $D f(1) h l^{b, c}$, it is possible that they uncover a pupal lethal(s) in these regions of the Shahrinau X-chromosome. It should be mentioned, however, that $D f(1) c t^{4 b l} / D f(1) s n^{\text {c128 }}$ females, being heterozygous deficient for 7B2-3; 7C3-4 and 7D1-2; 7D5-6, respectively, are perfectly viable and fertile. The fact that heterozygous $D f(1) h l^{b, c} /+++$ females, deficient for region $7 \mathbf{B} 8$; 7D18, are produced almost in wild-type progenynumber suggests that region 7D18-19; 7E1-2 may contain a vital gene(s) for pupal development. Also, the fact that these females are already deficiency-heterozygous for a Minute is very likely to make them still less viable.

\section{Development}

In order to see whether the deficiency heterozygotes were delayed in development, eggs from the different crosses were allowed to develop at $17^{\circ}, 25^{\circ}$, and $29^{\circ} \mathrm{C}$. The results of these experiments are shown in fig. 2 , and it can be seen that deficiency heterozygotes hatch 6-8, 4 , and 2-3 days later at 


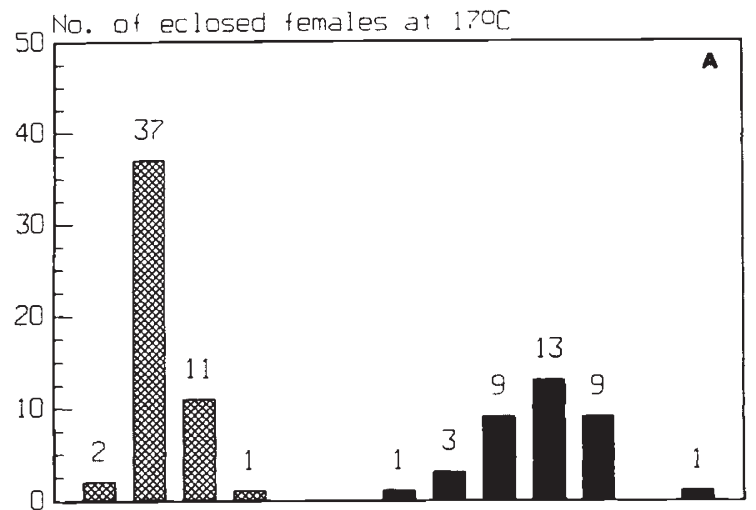

$\begin{array}{lllllllllllll}21 & 22 & 23 & 24 & 25 & 26 & 27 & 28 & 29 & 30 & 31 & 32 & 33\end{array}$
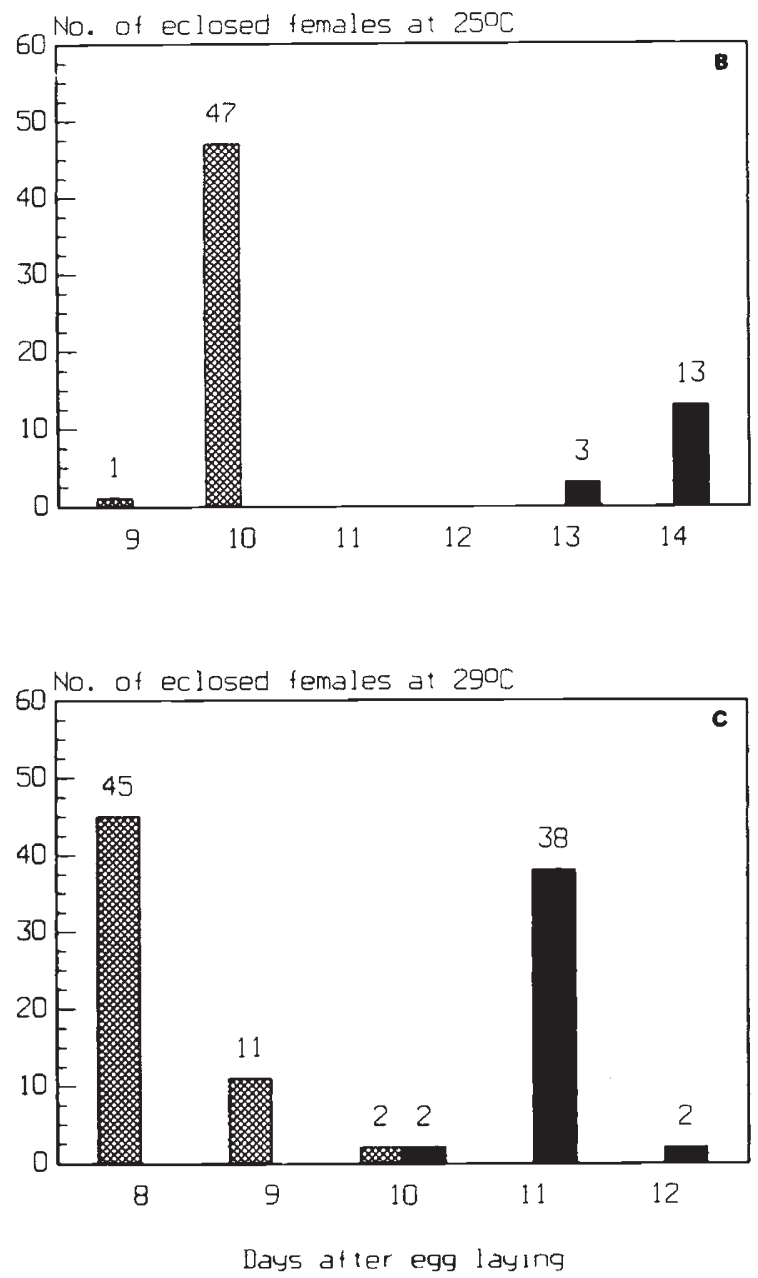

Figure 2 Developmental time (from egg to adult) for wild-type and Minute females at $17^{\circ} \mathrm{C}(\mathrm{A}), 25^{\circ} \mathrm{C}(\mathrm{B})$, and $29^{\circ} \mathrm{C}(\mathrm{C})$. Cross-hatched bars, wild-type; and filled bars, Minute. For further details see Materials and Methods. these temperatures, respectively, in comparison with heterozygous deficient flies carrying $D p(1 ; 2) s n^{+72 d}$. The results show that these deficiency heterozygotes have extremely retarded development, which is typical for Minutes. When analyzing the developmental time for the different stages we found that the delay occurred solely during the larval period.

\section{Sterility of deficiency heterozygotes}

The fertility of Minute females that eclosed at the different temperatures was checked by crossing them individually to 3-5 wild-type males. If no eggs were laid after 4 days the males were replaced by males from another wild-type strain. At $25^{\circ} \mathrm{C}$ we found that $\sim 50$ per cent of these females were sterile, and the number of eggs laid varied from zero to that of a wild-type female. Analyzing the ovaries we found that in most cases they were normally developed, even those of females not laying any eggs. However, the common oviduct was often too narrow to allow the eggs to pass through. In some cases the ovaries appeared to be undeveloped, and the maturation time prolonged in comparison with wild-type.

The fertility of the Minute females was markedly reduced at $17^{\circ}$ as well as $29^{\circ} \mathrm{C}$. This result is not in accordance with the viability results, which showed a better viability at these temperatures. We did not address this problem any further.

\section{Morphology}

When examining the deficiency heterozygotes for morphological divergence relative to wild-type we observed that they had shorter and finer bristles, rough and somewhat larger eyes, thin-textured wings with a tendency to plexus venation, missing aristae, and affected antennae (fig. $3(\mathrm{~A}, \mathrm{~B})$ ). It is particularly obvious that segments 4,5 , and 6 are affected, and that the number of aristae is greater on affected antennae. All the above-mentioned features are typical for Minutes (Lindsley and Grell, 1968). In addition, we observed flies with alterations to the morphology of the third pair of legs. On the other hand, we observed no reduction in body size, which is often seen in Minute heterozygotes (Lindsley and Grell, 1968).

\section{Minute maternal effects}

When examining the fecundity of Minute females at $25^{\circ} \mathrm{C}$ we observed that many embryos and larvae died, and of 253 females hatched only two were 


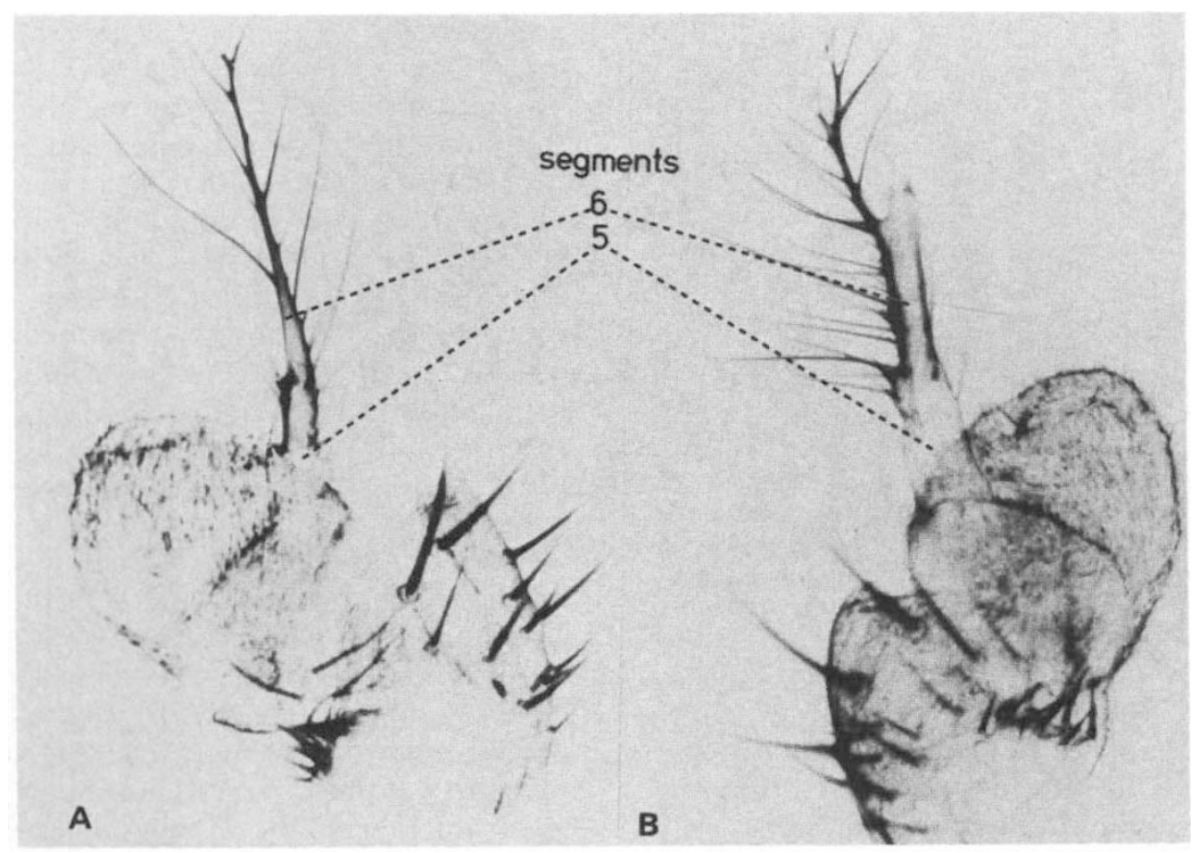

Figure 3 Morphological effects of the $M(1) 7 C$ mutation. (A) shows a normal antenna, and (B) demonstrates a typical Minute antenna observed in the present study.

Minute instead of the expected 1:1 ratio. Furthermore, both Minute and non-Minute adult progeny showed Minute maternal effects like abdominal segmentation defects, fused tergites, and missing or defective legs and halteres. Of the non-Minute offspring 30 per cent of the females $(n=251)$ and 13 per cent of the males $(n=201)$ showed these maternal effects.

Minute maternal effects have been observed in embryos and larvae from $M(3) i^{55}$ and $M(3) 99 D$ mothers (Boring et al., 1989; Kongsuwan et al., 1985). Boring et al., (1989) also showed that protein synthesis in embryos from Minute mothers is lowered by $\sim 30$ per cent during the syncytial nuclear cycles of early embryogenesis, and that the segmentation gene fushi tarazu $(f t z)$ exhibits abnormal expression patterns at the cellular blastoderm stage. The fact that it was possible to phenocopy these Minute maternal effects with low doses of cycloheximide (an inhibitor of protein synthesis) supports the notion that the product of $M(3) i^{55}$ is involved in protein synthesis (Boring et al. 1989). Although we have no protein synthesis data on $M(1) 7 C$, the observed Minute maternal effects suggest that the product of this Minute is also involved in protein synthesis and thus indirectly may influence the expression of genes that are dependent on protein synthesis. It could be that the RPS14 (Brown et al., 1988) and $M(1) 7 C$ are the same gene.

\section{Northern blot analysis}

Total larval RNA from wild-type and two deficiency heterozygotes, $D f(1) h l^{b, c}$, and from wild-type ovaries was separated on agaroseformaldehyde gels, the nucleic acids were blotted onto GeneScreen Plus filters, and hybridized with pGS14-19 containing the duplicated gene for ribosomal protein RPS14. This gene was previously mapped to region 7C5-9 on the X-chromosome (Brown et al., 1988). The autoradiogram in fig. 4 reveals that the probe hybridizes to a single transcript of $\sim 650 \mathrm{~b}$ in the wild-type RNA, and that the accumulation of this transcript is extremely low in the two deficiency heterozygotes. This extremely low accumulation of RPS14 mRNA was a surprising observation since we expected the heterozygous deficiencies to accumulate at least 50 per cent of the wild-type amount. We have as yet no plausible explanation of this result. However, the finding implies that expression of RPS 14 is not balanced by dosage compensation in heterozygous deficient females, and suggests that dosage com- 


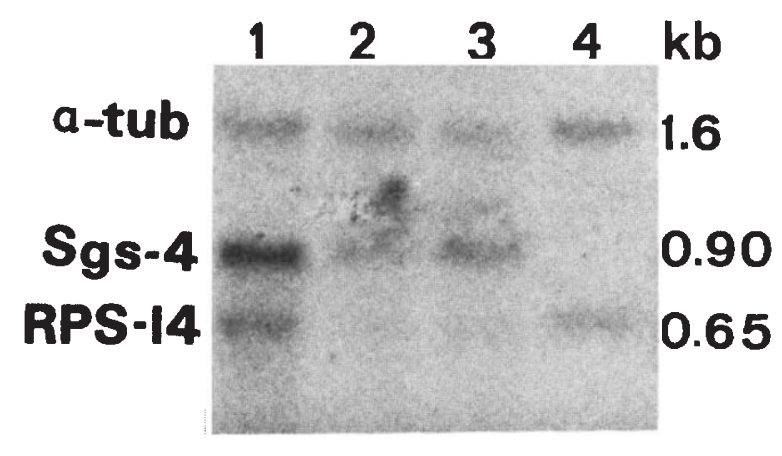

Figure 4 Northern blot of total RNA from (1) wild-type; (2) $D f(1) h l^{b} /+++; b w^{D} /++($ Minute $) ;(3) D f(1) h l^{c} /+++$; $b w^{D} /++($ Minute $)$ larvae; and (4) wild-type ovaries. $8 \mu \mathrm{g}$ of RNA was loaded in each lane, and after electrophoresis the RNA was blotted onto GeneScreen filter. Probes pGS14-19 and $\alpha$-tub were used simultaneously, and probe pRH0.75 after having deprobed the filter.

pensation mechanisms function by down-regulating female $\mathrm{X}$-linked loci. The fact that the RPS 14 gene is duplicated does not apparently solve this problem in deficiency heterozygotes (Brown et al., 1988). Note that the accumulation of $\alpha$-tubulin mRNA (internal standard) is not affected (fig. 4).

Probing with pRH0.75 DNA, a clone containing almost all of the $S g s-4$ gene (salivary gland secretion), revealed that Minute larvae accumulate $\sim 50$ per cent $S g s-4$ mRNA in comparison with wild-type (fig. 4). The expression of $S g s-4$ is regulated in a temporal and spatial way (Muskavitch and Hogness, 1980; Hansson and Lambertsson 1983). The steroid hormone ecdysterone is known to be involved, indirectly as well as directly, in the control of glue gene expression (Hansson and Lambertsson, 1983, 1989). Therefore, it could be that decreased protein synthesis rates may reduce the concentrations of factors that regulate the transcription of Sgs-4. These factors may not necessarily be parts of the translational machinery but could be mitochondrial enzymes as has been suggested for Minutes $M(2) L 2$ (Farnsworth, 1959) and $M(3) w$ (Treanor, 1962; Walker, 1985). On the other hand, the observed reduction of $S g s-4$ mRNA might be due to the Minute larvae not being in the same developmental stage as the wildtype ones. The tissue-specific expression of $\mathrm{Sgs}-4$ is seen in fig. 4, lane 4, which contains wild-type ovarian RNA.

By using the pGS14-19 clone we were able to localize unambiguously the RPS14 gene in the $\mathrm{X}$-chromosome. This was done by Southern analysis of a collection of 9 genomic lambda phage clones covering the region from $7 \mathrm{C} 3-4$ (dec-1; defective chorion-1) to 7D1-2 (sn; singed) using pGS14-19 as probe (results not shown). The clones were from a genomic lambda phage library of the D. melanogaster Shahrinau wild-type strain (A. Lambertsson, T. Johansson, and S. Andersson, unpublished results). We found that pGS14-19 hybridized to a clone $\sim 28 \mathrm{kbp}$ distal to clone $\mathrm{sn} 9$ (fig. 5). The latter clone contains the transcription startpoint of the singed locus, and was used as start probe in our chromosome walk to dec-1 (Roiha et al., 1988; K. O'Hare, personal communication; A. Lambertsson, T. Johansson, and S. Andersson, unpublished results). This result maps the $R P S 14$ gene to region $7 \mathrm{C} 8-9$, which is in agreement with the cytological mapping to 7C5-9 reported by Brown et al. (1988).

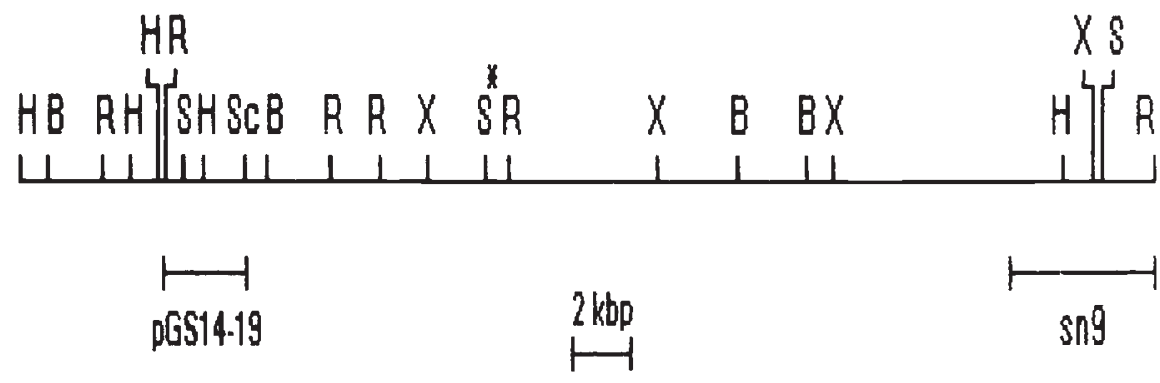

Figure 5 Restriction map of the region containing clones pGS14-19 and sn9. The distance between the two is $\sim 28 \mathrm{kbp}$; pGS14-19 and sn9 contain the duplicated RPS14 gene and the transcription startpoint of the singed locus, respectively. The distal to proximal orientation in the X-chromosome is from left to right (cf. fig. 1). B=BamHI, H=HindIII, R=EcoRI, S=SalI, $\mathrm{Sc}=$ SacI, and $\mathrm{X}=\mathrm{XhoI}$. The asterisked SalI site was not present in our Canton $\mathrm{S}$ wild-type stock although it was reported present in the Canton S strain used by Brown et al., 1988. 


\section{CONCLUSION}

We have identified a novel Minute locus, $M(1) 7 C$, on the X-chromosome of $D$. melanogaster. It has most, if not all, of the Minute features. We have also mapped the ribosomal protein gene RPS 14 to $\sim 28 \mathrm{kbp}$ distal from the singed locus; on the cytological map this is in region 7C8-9. The fact that $M(1) 7 C$ and $R P S 14$ both map to region 7C59, and that the accumulation of RPS 14 mRNA is extremely low in two deficiency heterozygotes (Minutes) makes it tempting to speculate that $M(1) 7 C$ and $R P S 14$ are the same gene.

Acknowledgements We are grateful to Dr Terrell K. Johnson for sharing unpublished information and Drosophila stocks. We thank Mr Thore Johansson for expert technical assistance, Drs D. Rhoads and D. Roufa, and M. Bownes for generously supplying the pGS14-19 and $\alpha$-tubulin clones, respectively, and Dr K. Lineruth for fruitful discussions. S. Andersson was supported by the Sven and Lilly Lawski foundation. This work was supported by the Swedish Natural Science Research Council.

\section{REFERENCES}

BORING, L. F., SINERVO, B. AND SCHUBINGER, G. 1989 Experimental phenocopy of a Minute maternal-effect mutation alters blastoderm determination in embryos of Drosophila melanogaster. Dev. Biol., 132, 343-354.

BROWN, S. J., RHOADS, D. D., STEWART, M. J., VAN SLYKE, B., CHEN, I.-T, JOHNSON, T. K., DENELL, R. E. AND ROUFA, D. J. 1988 Ribosomal protein S14 is encoded by a pair of highly conserved, adjacent genes on the X-chromosome of Drosophila melanogaster. Mol. Cell. Biol., 8, 4314-4321.

BURNS, D., STARK, B., MACKLIN, M. AND CHOOI, W. 1984. Isolation and characterization of cloned DNA sequences containing ribosomal protein genes of Drosophila melanogaster. Mol. Cell. Biol., 4, 2643-2652.
FARNSWORTH, M. W. 1959. Studies on isolated mitochondria of Minute and wild-type Drosophila. Rec. Genet. Soc. Am., 28,69 .

GANS, M., FORQUIGNON, F. AND MASSON, M. 1980. The role of dosage of the region 7D1-7D5-6 of the $\mathrm{X}$ chromosome in the production of homeotic transformations in Drosophila melanogaster. Genetics, 96, 887-902.

HANSSON, L. AND LAMBERTSSON, A. 1983. The role of $s u(f)$ gene function and ecdysterone in transcription of glue polypeptide mRNAs in Drosophila melanogaster. Molec. Gen. Genet., 192, 395-401.

HANSSON, L. AND LAMBERTSSON, A. 1989. Steroid regulation of glue protein genes in Drosophila melanogaster. Hereditas, $110,61-67$

KAY, M. A. AND JACOBS-LORENA, M. 1987. Developmental genetics of ribosome synthesis in Drosophila. Trends in Genetics, 3, 347-351.

KONGSUWAN, K., QIANG, Y., VINCENT, A., FRISARDI, M. C., ROSBASH, M., LENGYEL, J. A. AND MERRIAM, J. 1985. A Drosophila Minute gene encodes a ribosomal protein. Nature (London), 317, 555-558.

LEFEVRE JR., G. AND JOHNSON, T. K. 1973. Evidence for a sex-linked haplo-inviable locus in the cut-singed region of Drosophila melanogaster. Genetics, 74, 633-645.

LINDSLEY, D. L. AND GRELL, E. H. 1968. Genetic variations of Drosophila melanogaster. Carnegie Inst. Washington Publ., 627.

LINDSLEY, D. L. AND ZIMM, G. 1987. The genome of Drosophila melanogaster. Part 3: Rearrangements. Dros. Info. Serv., 65.

MUSKAVITCH, M. A. T. AND HOGNESS, D. S. 1980. Molecular analysis of a gene in a developmnentally regulated puff of Drosophila melanogaster. Proc. Natl Acad. Sci. USA, 77, $7362-7366$.

RITOSSA, F. M., ATWOOD, K. C. AND SPIEGELMAN, S. 1966. A molecular explanation of the bobbed mutants of Drosophila as partial deficiencies of ribosomal DNA. Genetics, 54, 663-676.

ROIHA, H., RUBIN, G. M. AND O'HARE, K. 1988. $P$ element insertions and rearrangements at the singed locus of Drosophila melanogaster. Genetics, 119, 75-83.

TREANOR, K. P. 1962. Effects of the $M(3) w$ factor on growth during the third instar of Drosophila melanogaster. Ph.D. Thesis, University of Buffalo, Buffalo, New York.

VASLET, C. A., O'CONNEL, P., IZQUIERDO, M. AND ROSBASH, M. 1980. Isolation and mapping of a cloned ribosomal protein gene of Drosophila melanogaster. Nature (London), $285,674-676$.

WALKER, V. K. 1985. Yolk polypeptide gene expression in Minute Drosophila females. Biochem. Genet., 23, 363-378. 